\title{
Efficacy, safety and tolerability of linezolid containing regimens in treating MDR-TB and XDR-TB: systematic review and meta-analysis
}

\author{
Giovanni Sotgiu, Rosella Centis, Lia D’Ambrosio, Jan-William C. Alffenaar, \\ Holly A. Anger, Jose A. Caminero, Paolo Castiglia, Saverio De Lorenzo, Giovanni Ferrara, \\ Won-Jung Koh, Giesela F. Schecter, Tae S. Shim, Rupak Singla, Alena Skrahina, \\ Antonio Spanevello, Zarir F. Udwadia, Miquel Villar, Elisabetta Zampogna, \\ Jean-Pierre Zellweger, Alimuddin Zumla and Giovanni Battista Migliori
}

ABSTRACT: Linezolid is used off-label to treat multidrug-resistant tuberculosis (MDR-TB) in absence of systematic evidence. We performed a systematic review and meta-analysis on efficacy, safety and tolerability of linezolid-containing regimes based on individual data analysis.

12 studies (11 countries from three continents) reporting complete information on safety, tolerability, efficacy of linezolid-containing regimes in treating MDR-TB cases were identified based on Preferred Reporting Items for Systematic Reviews and Meta-Analyses guidelines. Metaanalysis was performed using the individual data of 121 patients with a definite treatment outcome (cure, completion, death or failure).

Most MDR-TB cases achieved sputum smear (86 (92.5\%) out of 93 ) and culture (100 (93.5\%) out of 107) conversion after treatment with individualised regimens containing linezolid (median (inter-quartile range) times for smear and culture conversions were 43.5 (21-90) and 61 (29119) days, respectively) and 99 (81.8\%) out of 121 patients were successfully treated. No significant differences were detected in the subgroup efficacy analysis (daily linezolid dosage $\leqslant 600 \mathrm{mg}$ versus $>600 \mathrm{mg}$ ). Adverse events were observed in $63(58.9 \%)$ out of 107 patients, of which $54(68.4 \%)$ out of 79 were major adverse events that included anaemia $(38.1 \%)$, peripheral neuropathy $(47.1 \%)$, gastro-intestinal disorders $(16.7 \%)$, optic neuritis $(13.2 \%)$ and thrombocytopenia (11.8\%). The proportion of adverse events was significantly higher when the linezolid daily dosage exceeded $600 \mathrm{mg}$.

The study results suggest an excellent efficacy but also the necessity of caution in the prescription of linezolid.

KEYWORDS: Efficacy, extensively drug-resistant tuberculosis, linezolid, multidrug-resistant tuberculosis, safety, tolerability

$\mathbf{T}$ uberculosis (TB) is a leading cause of morbidity and death worldwide. In the past decades cases of drug-resistant TB, particularly multidrug-resistant tuberculosis (MDR-TB; defined as in vitro resistance to at least isoniazid and rifampicin, the two most potent first-line drugs for TB treatment) and extensively drug-resistant TB (XDR-TB; defined as in vitro resistance to isoniazid and rifampicin plus any fluoroquinolone and at least one of the second-line injectable drugs: amikacin, capreomycin or kanamycin), have been described in almost all countries that have been surveyed [1-3].
Management of MDR-TB and XDR-TB is still a major problem from both a clinical and public health perspective [1-5]. Evidence has shown that anti-TB treatment outcomes for "complicated" MDR-TB (e.g. those with additional resistance beyond isoniazid and rifampicin) and XDR-TB cases are still sub-optimal, highlighting an urgent need for information on safety, tolerability and efficacy of new antibiotics [6-15].

In vitro and pharmacological data suggest that linezolid, an oxazolidinone antibiotic, could be
AFFILIATIONS

For a full list of affiliations details please see the Acknowledgements section.

CORRESPONDENCE

G.B. Migliori

World Health Organization

Collaborating Centre for Tuberculosis and Lung Diseases

Fondazione S. Maugeri

Care and Research Institute

Via Roncaccio 16

21049

Tradate

Italy

E-mail: giovannibattista.migliori@

fsm.it

Received:

Feb 072012

Accepted after revision:

March 192012

First published online:

April 102012 
efficacious in treating mycobacterial infections, including MDR-TB [16-21].

Nevertheless, clinical experience on linezolid has been mainly restricted to case reports and small case series including both non-tuberculous mycobacterial diseases and TB [22-29].

Due to the lack of available antibiotics to treat such difficult cases, linezolid is already used off-label to treat MDR-TB in several countries, despite the absence of randomised controlled clinical trials to assess efficacy, safety and tolerability and also large retrospective and prospective observational studies [8, 13, 15].

Data on the use of linezolid to treat MDR-TB is limited. At present, only seven cohorts published on linezolid include more than 10 cases, their size ranging between 12 and 85 cases (of which only 45 had information on efficacy) [8, 30-35].

In the recent debate surrounding the use of new anti-TB drugs [36-37], the role and contribution to treatment success of linezolid has generated much interest due to several reasons. First, the limited evidence available shows that the drug is very active against Mycobacterium tuberculosis, although, it has a high price. Secondly, several adverse events have been attributed to linezolid: up to $41.2 \%$ of patients experienced major adverse events (mainly anaemia, thrombocytopenia and polyneuropathy) in the largest published cohort [8]. Thirdly, the correct dose, optimising efficacy and tolerability has not yet been defined [38-40]. The possible role of linezolid in future short regimens critically depends on the answer to the following questions. What is the correct dosage and necessary duration of exposure? Is it really effective? Does its safety and tolerability allow for administration over a sufficient duration to ensure efficacy?

To further support the development of evidence-based guidance on the use of linezolid in difficult-to-treat MDR-TB and XDR-TB cases, we present the results of a systematic review and a meta-analysis on efficacy, safety and tolerability of linezolid that has been based on individual data analysis.

\section{MATERIALS AND METHODS}

\section{Search strategy}

We identified clinical studies evaluating linezolid to treat MDR-TB and XDR-TB cases.

We searched computerised bibliographic databases, PubMed and EMBASE, from January 2001 through to October 2011. In addition we checked all abstracts published over the same period in the International Journal of Tuberculosis and Lung Disease.

Combinations of the following search terms were used: "tuberculosis", "multidrug-resistant tuberculosis", " extensively drug-resistant tuberculosis", "MDR", "XDR", "safety", "tolerability", "efficacy" and "linezolid". We restricted our search to publications in English. Unpublished sources of data were not included, as the evaluation of their quality in absence of a peerreview process could not be ensured. We also manually searched bibliographies of retrieved articles and existing systematic reviews and meta-analyses on MDR-/XDR-TB for additional references.

\section{Study selection}

We included studies that reported complete information on safety, tolerability and efficacy of linezolid in treating culture-confirmed MDR-TB and XDR-TB cases in humans involving $\geqslant$ five adult individuals (proportion of paediatric patients was required to be $<25 \%$ of the total cohort).

The following studies were excluded: 1 ) case reports with $<$ five cases, editorials and reviews on linezolid; 2) laboratory studies; 3) animal studies; and 4) studies where MDR-TB and XDR-TB were not confirmed by $M$. tuberculosis culture and drug susceptibility testing (DST) in quality-assured laboratories.

Studies not reporting the core pieces of information necessary for the analysis were excluded in a second round of selection (e.g. after failing to obtain the information from the Authors, as described in the Data extraction section). In efficacy analysis bacteriological conversion and definite outcomes were defined as described in LASERSON et al. [41].

For safety and tolerability analysis, variables of interest included: linezolid dose and duration of exposure to linezolid-containing regimens; existing adverse events; description of adverse events (major, defined as those requiring interruption of the drug or adjustment of the dosage, and minor) [8]; and time of occurrence of the adverse events.

Citations were independently screened by three investigators (E. Zampogna (EZ), R. Centis (RC) and G. Ferrara (GF)) by examining titles and abstracts to identify potentially relevant studies, and differences were resolved by consensus (G.B. Migliori (GBM) and G. Sotgiu (GS)). These original articles were then retrieved and the full text screened for final inclusion and data extraction.

\section{Data extraction}

A standardised electronic ad hoc form for data extraction was designed. Three reviewers (EZ, RC and GF) analysed and crosschecked all selected articles independently and extracted data. In case of deviations, final documentation of data was based on consensus (GBM and GS). The inter-rater agreement obtained for the data from the included studies was $\sim 100 \%$.

Senior and/or correspondence authors of the selected papers were contacted by email in order to verify the accuracy of the abstraction and obtain missing information in the texts; including potentially useful information for the evaluation of the efficacy, safety, and tolerability profiles of the linezolid-based regimens.

Anonymous individual data were extracted and confirmed by the senior and/or correspondence authors of the included manuscripts. For the efficacy analysis the following variables were collected: time to sputum smear conversion and culture conversion, and final treatment outcome.

For the safety and tolerability analysis the recorded covariates were: daily linezolid dosage and duration of exposure to linezolid-containing regimens; adverse events; description of the adverse event; and time of occurrence of the adverse event.

In addition, the following variables were collected: calendar period of the study; country in which the study was conducted; sex; age; multidrug regimen prescribed in combination or in addition to linezolid (drugs, dose and duration); drug resistance profile; history of previous treatment; number of previous treatment regimens longer than 30 days. 
No ethical clearance was requested for this anonymous epidemiological analysis, since all selected studies had previously received approval from local institutional review boards.

\section{Study quality assessment}

This systematic review and meta-analysis was performed according to the guidelines of the Preferred Reporting Items for Systematic Reviews and Meta-Analyses (PRISMA) [42].

The inter-rater agreement obtained for the study selection and data extraction from the included studies was $>95 \%$; discrepancies were resolved by consensus (GBM and GS).

\section{Statistical analysis}

Descriptive, both qualitative and quantitative, variables were summarised with proportions, medians and interquartile ranges (IQR); they were compared using the Chi-squared test and the Wilcoxon Mann-Whitney test, respectively.

Meta-analytic computations were performed using individual data taken from patients with a definite treatment outcome (cure, treatment completion, death, or treatment failure) [41]. Random-effects models were used to account for the predicted between-study dispersion. Forest plots were used to graphically evaluate both the variability (i.e. 95\% CI) of the point estimates for the efficacy/safety-related covariates and the weight of every cohort size in the computation of the pooled estimates. Inconsistency among included studies was assessed by the Chi-squared test for heterogeneity; the inconsistency $\left(\mathrm{I}^{2}\right)$ statistic assesses the role of true variability rather than sampling error on the overall variation.

Subgroup analyses focused on the safety, efficacy and tolerability of linezolid and were performed between patients treated with a daily regimen of $\leqslant 600 \mathrm{mg}$ linezolid versus those treated with a daily regimen of $>600 \mathrm{mg}$ linezolid. p-values $<0.05$ were regarded as statistically significant. Statistical analyses were performed with the Stata 9.0 (StataCorp LP, College Station, TX, USA) and Meta-Disc Version 1.4 [43] software.

\section{RESULTS}

\section{Selection of the studies}

The scientific literature search identified 88 citations. 12 clinical studies were selected, as summarised in the PRISMA flowchart (fig. 1). The characteristics of the studies and the number of cases analysed in the systematic review and meta-analysis are summarised in table 1 . The senior and/or correspondence author of $10(83.3 \%)$ out of 12 studies [8, 30-35, 44-47] responded to the electronic invitation to provide demographic, epidemiological and clinical information missing in the full texts of the retrieved manuscripts.

\section{Characteristics of the selected studies}

Six $(50 \%)$ out of the 12 studies [8, 22, 33, 35, 44, 47] were conducted in Europe, four (33.3\%) out of the 12 in Asia [31, 32, 45, $46]$, and two $(16.7 \%)$ out of the 12 in the USA [30, 34] (table 2). Eight $(66.7 \%)$ out of 12 were retrospective observational studies $[8,22,30,34-35,44-46]$ while four $(33.3 \%)$ out of 12 were prospective [31-33, 47]. The majority $(66.7 \%$, eight out of 12$)$ of the studies were performed in single, university or tertiary, in/ outpatient settings [22, 31-32, 35, 44-47].

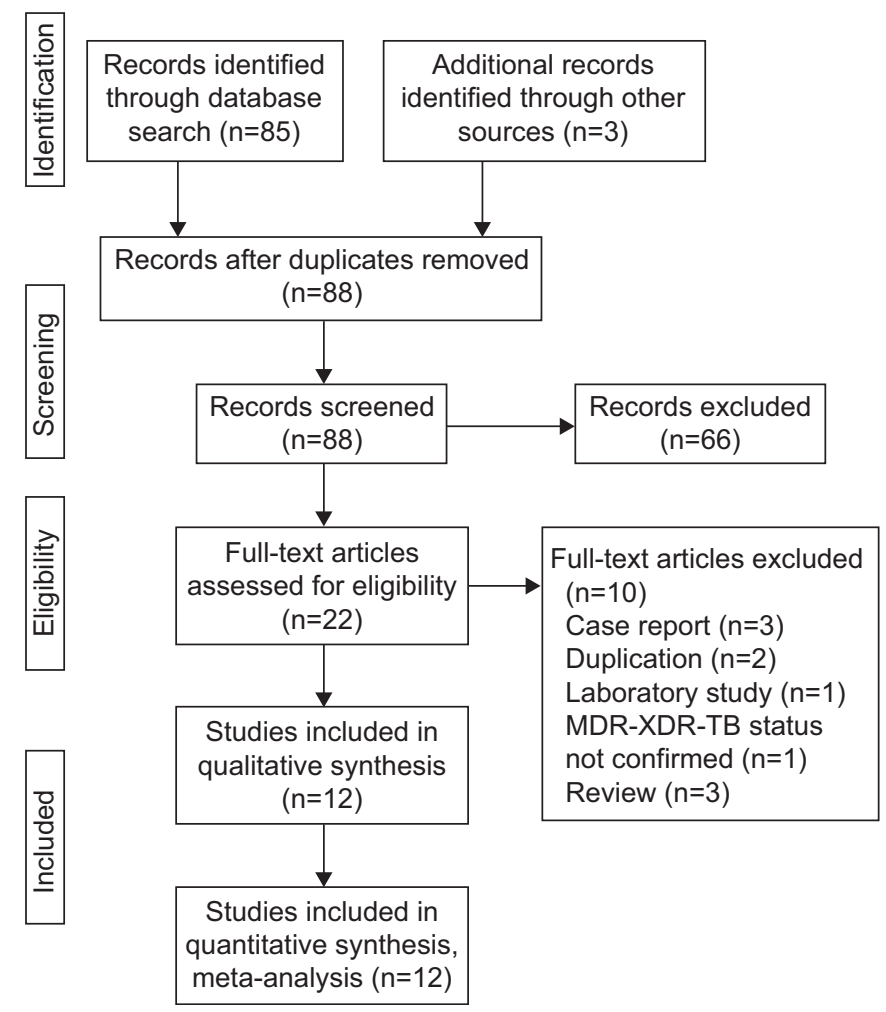

FIGURE 1. PRISMA flowchart of enrolled studies for systematic review. MDR: multidrug-resistant; XDR-TB: entensively drug-resistant tuberculosis.

Linezolid treatment was administered in an unblinded and nonrandomised manner; all study designs were planned without a control group (table 3 ) except the multicentre study by MigLiORI et al. [8]; one (8.3\%) out of 12 . All but two TB patients who were enrolled in the prospective or retrospective studies were aged $\geqslant 15$ yrs $[8,22,30-32,35,44-47]$ and all were given individualised anti-TB therapy based on the results of the DST $[8,22,30-35,44-47]$. Linezolid dosages ranged from $300 \mathrm{mg}$ b.i.d. [22, 46, 47] to $400 \mathrm{mg}$ q.d. or b.i.d. [34], and $450 \mathrm{mg}$ q.d. [30] to $600 \mathrm{mg}$ q.d. $[8,30-33,34,35,45,46]$, b.i.d. $[8,22,31,33-35,44$, 47] or three times a week [30].

\section{Characteristics of the international cohort}

Individual data from 121 patients treated with linezolid in clinical settings located all over the world (i.e. Europe, North America, and Asia) [8, 22, 30-35, 44-47] were collected (tables 1 and 4$)$. More than half were males (53.7\%) and were born in Asian countries (69.3\%), with a median (IQR) age at treatment onset of 32 (25-41) yrs. Known risk factors favouring the development of TB and MDR-/XDR-TB were detected in several patients: $35.4 \%$ were migrants from high TB-burden countries; $8.7 \%$ were HIV positive; and $76.9 \%$ were previously treated with anti-TB therapy $>30$ days (median (IQR) for the number of times exposed to anti-TB drugs was $1(0-4)$ ). Almost all individuals with pulmonary TB were sputum smear-positive (102 (92.7\%) out of 110) and showed cavitary lesions at the baseline chest-radiograph examination (79 (74.5\%). out of 106). XDR-TB was diagnosed in $32.5 \%$ of the individuals $\left(\mathrm{I}^{2}=67.0 \%\right.$; fig. 2). One fourth of the cases underwent surgery because of the lack of sufficient active drugs or as adjunct intervention. Of the 


\begin{tabular}{|c|c|c|c|}
\hline TABLE 1 & \multicolumn{3}{|c|}{$\begin{array}{l}\text { Cases included in the systematic review and } \\
\text { meta-analysis in the } 12 \text { studies selected }\end{array}$} \\
\hline \multicolumn{2}{|c|}{ First author [ref.] } & $\begin{array}{l}\text { Systematic review } \\
\text { treatment outcome: } \\
\text { definite*, still on } \\
\text { treatment, default, } \\
\text { transferred out }\end{array}$ & $\begin{array}{l}\text { Meta-analysis } \\
\text { treatment outcome: } \\
\text { definite }{ }^{*} \text { only }\end{array}$ \\
\hline \multicolumn{2}{|c|}{ AlffenaAR [47] } & 8 & 8 \\
\hline \multicolumn{2}{|l|}{ ANGER [34] } & 16 & 15 \\
\hline \multicolumn{2}{|c|}{ DE LoRENZO [35] } & 12 & 3 \\
\hline \multicolumn{2}{|c|}{ FORTÚN [22] } & 5 & 4 \\
\hline \multicolumn{2}{|l|}{ NAM [46] } & 11 & 11 \\
\hline \multicolumn{2}{|c|}{ MIGLIORI [8] ${ }^{+}$} & 44 & 4 \\
\hline \multicolumn{2}{|l|}{ PARK [45] } & 8 & 7 \\
\hline \multicolumn{2}{|c|}{ SCHECTER [30] } & 30 & 23 \\
\hline \multicolumn{2}{|l|}{ SingLA [31] } & 29 & 14 \\
\hline \multicolumn{2}{|c|}{ UDWADIA [32] } & 18 & 13 \\
\hline \multicolumn{2}{|l|}{ VILLAR [33] } & 16 & 9 \\
\hline \multicolumn{2}{|c|}{ VON DER LIPPE [44]" } & 10 & 10 \\
\hline \multicolumn{2}{|c|}{ Total number of cases } & 207 & 121 \\
\hline
\end{tabular}

Data are presented as $\mathrm{n}$. "\#: definite was defined as: cured, treatment completed, died or failure; $"$ : authors of the studies meeting the inclusion criteria, where individual data was available in the manuscript but the correspondence/senior author did not provide the individual data-set; ${ }^{+}$: data from the German cohort were not included in the meta-analysis.

51 patients with data on hospital stay, discharge occurred after a median (IQR) duration of hospital stay of 39 (15-82) days.

No statistically significant demographic, epidemiological and clinical characteristics were detected between those treated with a daily dosage of linezolid $\leqslant 600 \mathrm{mg}$ (72 (59.5\%) out of 121$)$, and those treated with a daily dosage $>600 \mathrm{mg}$ (49 (40.5\%) out of 121) except for the covariates "migration", "HIV positivity" and "surgery", which were significantly more frequent in the group of patients exposed to a daily dose $>600 \mathrm{mg}$.

\section{Efficacy of regimes containing linezolid}

The majority of individuals converted to sputum smear (86 $(92.5 \%)$ out of $\left.93 ; \mathrm{I}^{2}=22.9 \%\right)$ and culture $(100(93.5 \%)$ out of $107 ; \mathrm{I}^{2}=18.2 \%$ ) negativity after the exposure to individualised linezolid-containing regimens (table 5 and fig. 3); median (IQR) time to sputum smear and culture conversion was 43.5 (21-90) and 61 (29-119) days, respectively.

More than $80 \%$ were successfully treated (99 (81.8\%) out of 121 ; $\mathrm{I}^{2}=44.8 \%$ ), while death and treatment failure were observed in $14.1 \%$ and $4.1 \%$ of the enrolled subjects, respectively (fig. 4) [41].

No statistically significant differences were detected in the subgroup efficacy analysis (daily linezolid dosage $\leqslant 600 \mathrm{mg}$ versus $>600 \mathrm{mg}$ ); proportion of cure was $\sim 80 \%$ in both groups and the rate of death and treatment failure occurred in less than one-fourth in both groups, respectively.

\section{Safety and tolerability of linezolid}

Approximately one out of every two patients (63 (58.9\%) out of $107 ; \mathrm{I}^{2}=82.2 \%$ ) experienced adverse events attributed to linezolid including $54(68.4 \%)$ out of 79 patients $\left(\mathrm{I}^{2}=73.1 \%\right)$ with major adverse events, i.e. they required linezolid treatment interruption or dosage reduction (table 6 and fig. 5). The main adverse events were anaemia $\left(38.1 \% ; \mathrm{I}^{2}=69.7 \%\right)$ and peripheral neuropathy $\left(47.1 \%\right.$; $\mathrm{I}^{2}=44.0 \%$ ) (fig. 6); other haematological and non-haematological adverse events occurred in a lower proportion of cases, i.e. gastro-intestinal disorders $(16.7 \%)$, optic neuritis $(13.2 \%)$ and thrombocytopenia $(11.8 \%)$.

A statistically significant higher risk of adverse events attributed to linezolid treatment was detected in the cohort treated with a linezolid daily dosage $>600 \mathrm{mg}$ ( $74.5 \%$ versus $46.7 \%)$. In particular, a statistically significant higher probability of anaemia ( $60 \%$ versus $2.5 \%$; $=0.0005)$, leukopoenia $(17.1 \%$ versus $2.0 \%$; $\mathrm{p}=0.012)$ and gastrointestinal symptoms $(29.4 \%$ versus $8.0 \%$; $\mathrm{p}=0.01$ ) was found despite a lower statistically significant

TABLE 2 Epidemiological characteristics of the selected studies

\begin{tabular}{|c|c|c|c|c|}
\hline First author [ref.] & Country & Study design & Clinical setting & Study duration yr \\
\hline ALFFEnAar [47] & The Netherlands & $\begin{array}{l}\text { Open-label, prospective, } \\
\text { pharmacokinetic }\end{array}$ & Monocentre, university medical centre & $2007-2008$ \\
\hline ANGER [34] & USA & Retrospective & Multicentre, public and private clinics & 2000-2006 \\
\hline DE LORENZO [35] & Italy & Retrospective & Monocentre, tuberculosis reference centre & 2009-2010 \\
\hline FORTÚN [22] & Spain & Retrospective & Monocentre, Ramon y Cajal Hospital (Madrid, Spain) & 1999-2004 \\
\hline NAM [46] & South Korea & Retrospective & Monocentre, university medical centre & 2004-2007 \\
\hline MIGLIORI [8] & $\begin{array}{l}\text { Belarus, Germany, Italy, } \\
\text { Switzerland }\end{array}$ & $\begin{array}{l}\text { Retrospective, controlled, } \\
\text { nonrandomised, unblinded }\end{array}$ & $\begin{array}{c}\text { Multicentre, } 21 \text { public hospitals and tuberculosis } \\
\text { reference centres }\end{array}$ & 2001-2007 \\
\hline PARK [45] & South Korea & Retrospective & Monocentre, university medical centre & 2003-2006 \\
\hline SCHECTER [30] & USA & Retrospective & Multicentre, public clinics & 2003-2007 \\
\hline SINGLA [31] & India & Prospective & Monocentre, tertiary centre & 2006-2011 \\
\hline UDWADIA [32] & India & Prospective, nonrandomised & Monocentre, private tertiary centre & 2000-2007 \\
\hline VILLAR [33] & Portugal & Prospective & Multicentre, public clinics & 2004-2009 \\
\hline VON DER LIPPE [44] & Norway & Retrospective & Monocentre, university medical centre & 1998-2002 \\
\hline
\end{tabular}


TABLE 3 Characteristics of the patients and of the anti-tuberculosis (TB) treatment in the selected studies

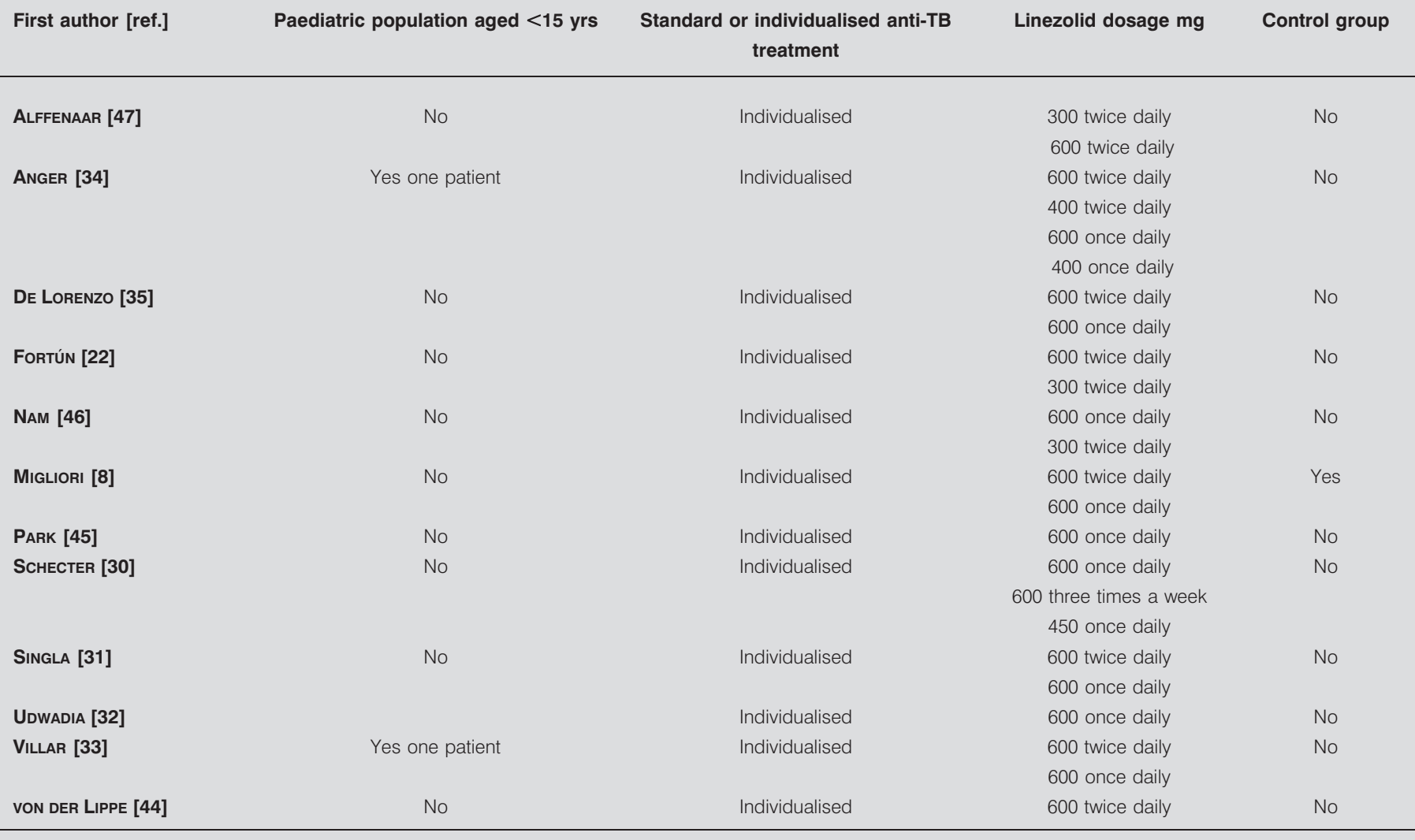

TABLE 4 Demographic, epidemiological and clinical characteristics of 121 multidrug-resistant tuberculosis (TB) cases enrolled in the meta-analysis

\begin{tabular}{|c|c|c|c|c|}
\hline & Total & LNZ daily dose $\leqslant 600 \mathrm{mg}$ & LNZ daily dose $>600 \mathrm{mg}$ & $\mathrm{p}$-value \\
\hline Male & $65 / 121(53.7)$ & $40 / 72(55.6)$ & $25 / 49(51.0)$ & 0.62 \\
\hline \multicolumn{5}{|l|}{ Country of birth } \\
\hline Europe & $12 / 75(16.0)$ & 2/45 (4.4) & 10/30 (33.3) & 0.0008 \\
\hline Asia & $52 / 75(69.3)$ & $37 / 45(82.2)$ & $15 / 30(50.0)$ & 0.003 \\
\hline Migrant & 29/82 (35.4) & $9 / 45(20.0)$ & 20/37 (54.1) & 0.001 \\
\hline HIV positive & 9/104 (8.7) & $0 / 55(0.0)$ & $9 / 49(18.4)$ & 0.0009 \\
\hline Previous exposure to anti-TB therapy $>1$ month & $93 / 121(76.9)$ & $51 / 72(70.8)$ & $42 / 49(85.7)$ & 0.06 \\
\hline Number of times treated with anti-TB drugs for $>1$ month & $1(0-4)$ & $1(0-4)$ & $1(0-3)$ & 0.81 \\
\hline Sputum-smear positive & $102 / 110(92.7)$ & $66 / 72(91.7)$ & $36 / 38(94.7)$ & 0.56 \\
\hline Pulmonary TB & $116 / 120(96.7)$ & $71 / 72(98.6)$ & 45/48 (93.8) & 0.15 \\
\hline Bilateral pulmonary involvement with cavitary lesions & 40/106 (37.7) & $26 / 69(37.7)$ & $14 / 37(37.8)$ & 0.99 \\
\hline Bilateral pulmonary involvement & $6 / 106(5.7)$ & $5 / 69(7.3)$ & $1 / 37(2.7)$ & 0.33 \\
\hline Non-cavitary unilateral pulmonary involvement & 21/106 (19.8) & $17 / 69(24.6)$ & $4 / 37(10.8)$ & 0.09 \\
\hline XDR-TB & $39 / 120(32.5)$ & $25 / 71(35.2)$ & $14 / 49(28.6)$ & 0.45 \\
\hline Surgical treatment & 27/108 (25.0) & $12 / 72(16.7)$ & $15 / 36(41.7)$ & 0.005 \\
\hline Hospital stay days & $39(15-82)$ & $37(12-79)$ & $60(19-159)$ & 0.37 \\
\hline
\end{tabular}

Data are presented as $\mathrm{n} / \mathrm{N}(\%)$ or median (interquartile range), unless otherwise stated. LNZ: linezolid; XDR-TB: extensively drug-resistant TB. 


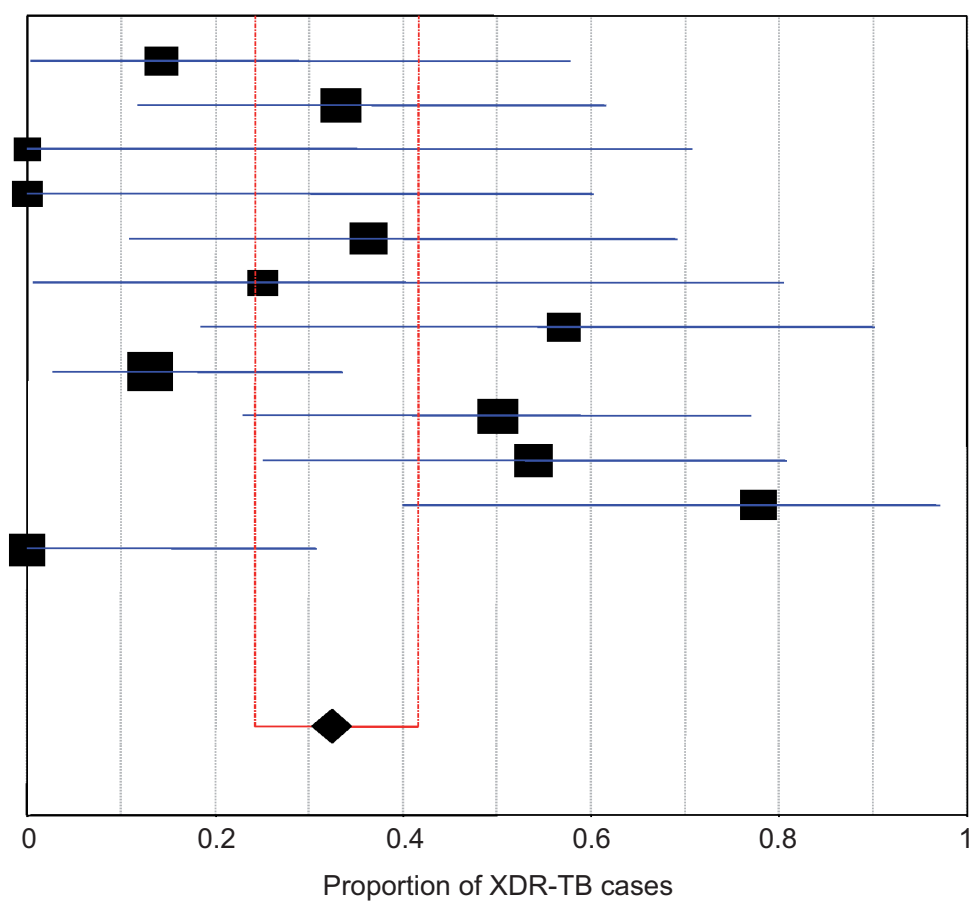

First author [ref.] Proportion of XDR-TB cases

$\begin{array}{lll}\text { ALFFENAAR [47] } & 0.14 & (0.00-0.58) \\ \text { ANGER [34] } & 0.33 & (0.12-0.62) \\ \text { DE LORENZO [35] } & 0.00 & (0.00-0.71) \\ \text { ForTÚN [22] } & 0.00 & (0.00-0.60) \\ \text { NAM [46] } & 0.36 & (0.11-0.69) \\ \text { MIGLIORI [8] } & 0.25 & (0.01-0.81) \\ \text { PARK [45] } & 0.57 & (0.18-0.90) \\ \text { SCHECTER [30] } & 0.13 & (0.03-0.34) \\ \text { SINGLA [31] } & 0.50 & (0.23-0.77) \\ \text { UdDWADIA [32] } & 0.54 & (0.25-0.81) \\ \text { VILLAR [33] } & 0.78 & (0.40-0.97) \\ \text { VON DER LIPPE [44] } & 0.00 & (0.00-0.31)\end{array}$

Pooled proportion $=0.33(0.24-0.42)$

Chi-squared=33.32; $d f=11 \quad(p=0.0005)$

$\left.\right|^{2}=67.0 \%$

FIGURE 2. Forest plot showing the proportions of extensively drug-resistant tuberculosis (XDR-TB) patients in the enrolled studies. Data are presented as $n$ (95\% Cl); $I^{2}$ inconsistency statistics; df: degrees of freedom.

exposure duration to linezolid (median (IQR) time of exposure: 252 (120-540) days versus 589.5 (154.5-750) days).

\section{DISCUSSION}

The main results of our study shed light on several areas relevant for the clinical use of linezolid, not described in previous observational studies: dosage and duration from one side and efficacy, safety and tolerability on the other side. The large sample size allowed more analyses and more robust inferences, not performed in the past.
This systematic review and meta-analysis of the efficacy, safety and tolerability of the linezolid-containing regimes is designed to support the development of future evidence-based guidance on the use of linezolid in difficult-to-treat MDR- and XDR-TB cases.

\section{Dosage and duration}

10 of the 12 clinical studies evaluated in the present analysis used linezolid at $600 \mathrm{mg} \cdot \mathrm{day}^{-1}$. This meta-analysis of data collected in different settings found no statistical difference in terms of treatment success, proportions of sputum smear or of

TABLE 5 Treatment outcomes of 121 multidrug-resistant tuberculosis (TB) cases enrolled in the meta-analysis

\begin{tabular}{|c|c|c|c|c|}
\hline & All treatments & $\begin{array}{l}\text { LNZ daily dose } \\
\leqslant 600 \mathrm{mg}\end{array}$ & $\begin{array}{l}\text { LNZ daily dose } \\
\quad>600 \mathrm{mg}\end{array}$ & p-value \\
\hline Patients treated with linezolid & & $72(59.5)$ & $49(40.5)$ & \\
\hline XDR-TB & & 25/71 (35.2) & 14/49 (28.6) & 0.45 \\
\hline Sputum smear conversion & $86 / 93(92.5)$ & $54 / 59(91.5)$ & $42 / 44(95.5)$ & 0.43 \\
\hline Culture conversion & 100/107 (93.5) & $54 / 59(91.5)$ & $46 / 48(95.8)$ & 0.37 \\
\hline Period from start of anti-TB therapy to sputum smear conversion days & $43.5(21-90)$ & $45.5(28-91)$ & $92.5(35-120)$ & 0.02 \\
\hline 2-month culture conversion & $37 / 72(51.4)$ & $18 / 42(42.9)$ & 19/30 (63.3) & 0.09 \\
\hline Period from start of anti-TB therapy to culture conversion days & $61(29-119)$ & $28(20-45)$ & $60(42-115)$ & 0.07 \\
\hline \multicolumn{5}{|l|}{ Definite treatment outcomes } \\
\hline Cured & $98 / 121(81.0)$ & $59 / 72(81.9)$ & $39 / 49(79.6)$ & 0.75 \\
\hline Treatment completed & $1 / 121(0.8)$ & $1 / 72(1.4)$ & & \\
\hline Died & $17 / 121(14.1)$ & $9 / 72(12.5)$ & $8 / 49$ (16.3) & 0.56 \\
\hline Failed & $5 / 121(4.1)$ & $3 / 72$ (4.2) & $2 / 49(4.1)$ & 0.98 \\
\hline
\end{tabular}

Data are presented as $\mathrm{n}(\%), \mathrm{n} / \mathrm{N}(\%)$ or median (interquartile range), unless otherwise stated. LNZ: linezolid; XDR-TB: extensively drug-resistant TB. 
a)

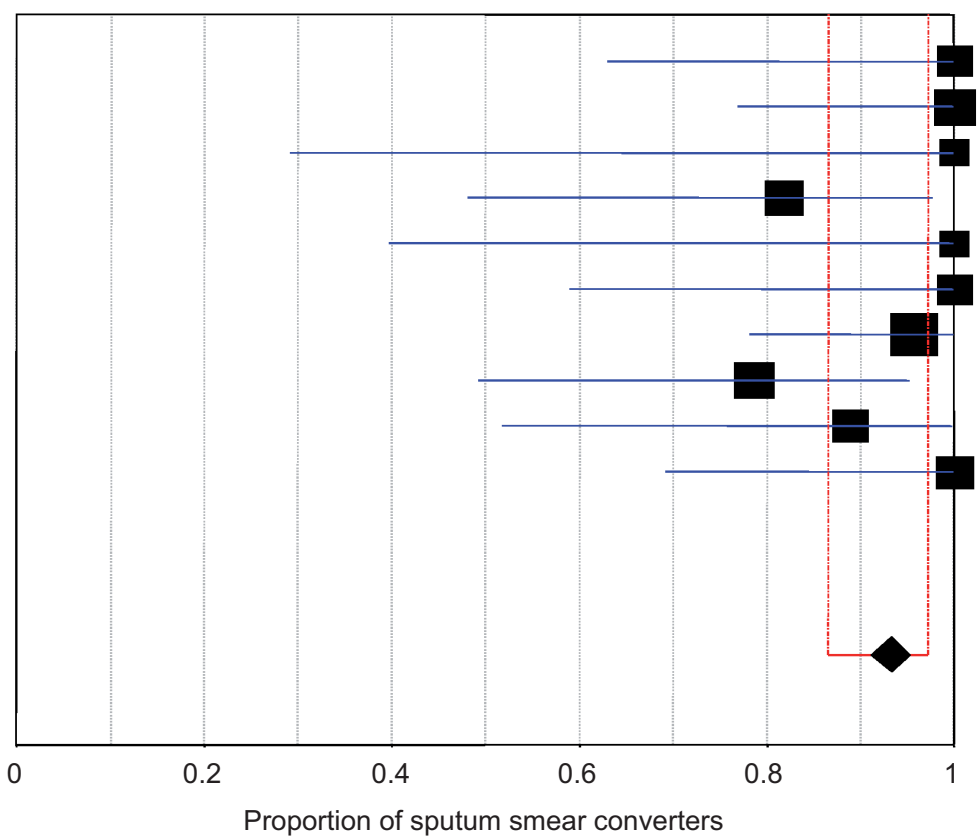

First author [ref.] Proportion of sputum smear converters

AlffenaAr [47]

ANGER [34]

1.00

$(0.63-1.00)$

De LoREnZo [35]

$1.00 \quad(0.77-1.00)$

$1.00 \quad(0.29-1.00)$

$0.82 \quad(0.48-0.98)$

$1.00 \quad(0.40-1.00)$

$1.00 \quad(0.59-1.00)$

$0.96 \quad(0.78-1.00)$

$0.79 \quad(0.49-0.95)$

$0.89 \quad(0.52-1.00)$

$1.00 \quad(0.69-1.00)$ b)

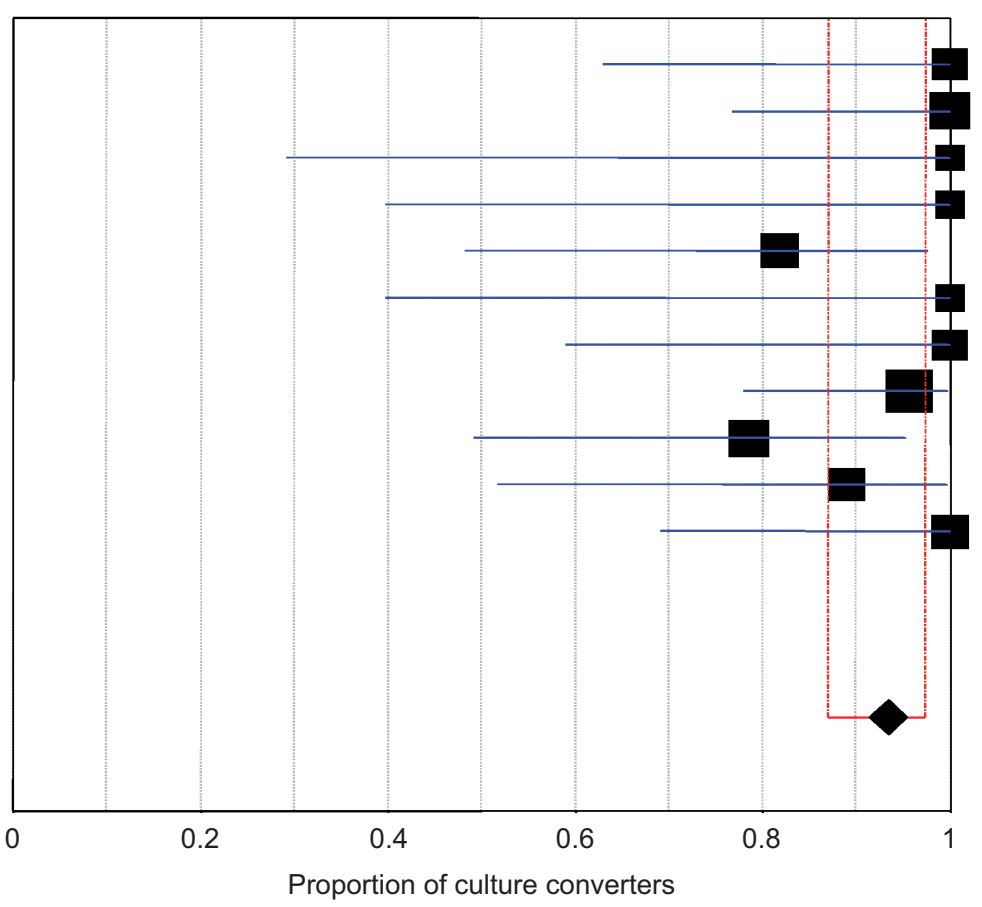

First author [ref.]

AlffenaAr [47]

Anger [34]

De LoRenzo [35]

FORTÚN [22]

NAM [46]

MIGLIORI [8]

PARK [45]

SCHECTER [30]

SINGLA [31]

VILLAR [33]

VON DER LIPPE [44]
Proportion of culture converters

$1.00 \quad(0.63-1.00)$

$1.00 \quad(0.77-1.00)$

$1.00 \quad(0.29-1.00)$

$1.00 \quad(0.40-0.98)$

$0.82 \quad(0.48-0.98)$

$1.00 \quad(0.40-1.00)$

$1.00 \quad(0.59-1.00)$

$0.96 \quad(0.78-1.00)$

$0.79 \quad(0.49-0.95)$

$0.89 \quad(0.52-1.00)$

$1.00 \quad(0.69-1.00)$

Pooled proportion $=0.93(0.87-0.97)$

Chi-squared=12.22; $d f=10 \quad(p=0.2704)$

$\mathrm{I}^{2}=18.2 \%$

FIGURE 3. Forest plots showing the proportion of a) sputum smear converters and b) culture converters in the enrolled studies. Data are presented as $\mathrm{n}(95 \% \mathrm{Cl}) ; \mathrm{I}^{2}$ : inconsistency statistics; df: degrees of freedom.

culture converters between those treated with $\leqslant 600 \mathrm{mg}$ q.d. versus those treated with $>600 \mathrm{mg}$ b.i.d.

Building on the evidence that a $600 \mathrm{mg}$ daily dose may decrease the occurrence of adverse events, while not compromising efficacy, a study by ALFFENAARet al. [47], provided a rationale for sub-dividing the total daily dose of $600 \mathrm{mg}$, in order to prevent the blood peaks probably responsible for the haematological and non-haematological related adverse events.

ALFFENAAR et al. [47] demonstrated that the serum concentrations of linezolid obtained following each $300 \mathrm{mg}$ administration b.i.d. are well above the minimum inhibitory concentration (MIC), i.e. $0.125-0.5 \mathrm{mg} \cdot \mathrm{L}^{-1}$ against $M$. tuberculosis $)$ and that the serum 


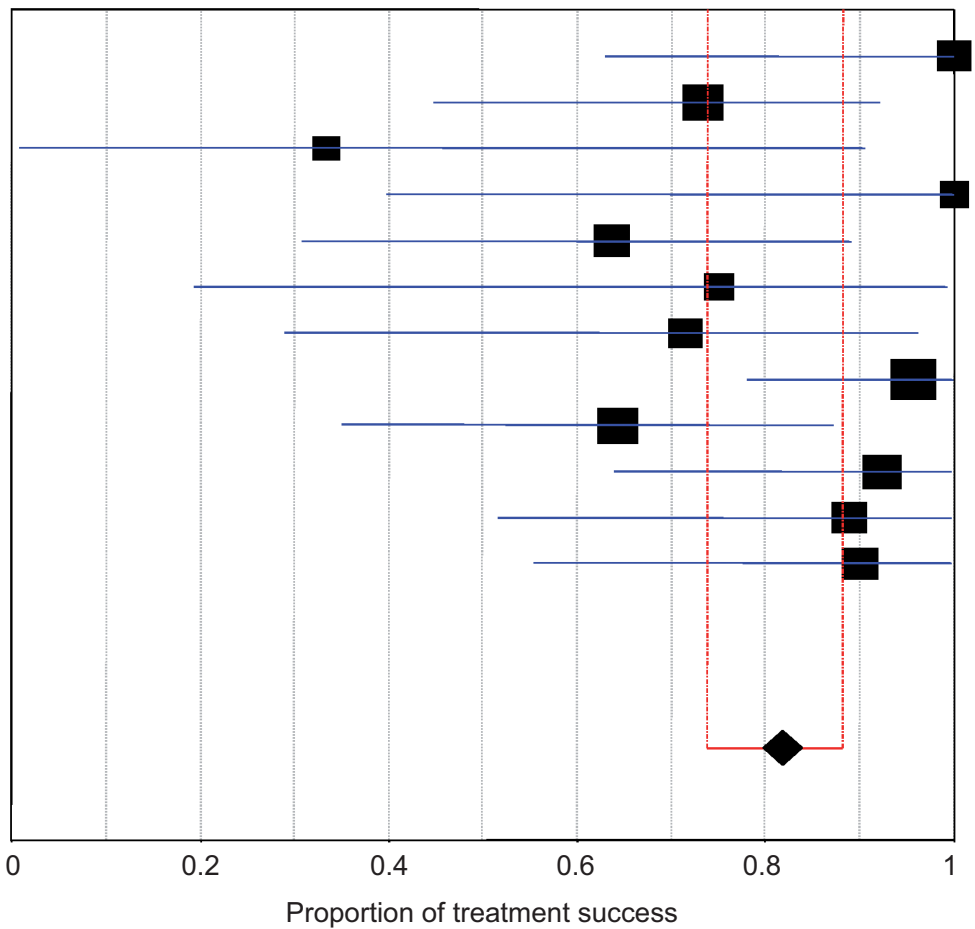

First author [ref.] Proportion of treatment success

$\begin{array}{lll}\text { AlFFENAAR [47] } & 1.00 & (0.63-1.00) \\ \text { ANGER [34] } & 0.73 & (0.45-0.92) \\ \text { DE LORENZO [35] } & 0.33 & (0.01-0.91) \\ \text { ForTÚN [22] } & 1.00 & (0.40-1.00) \\ \text { NAM [46] } & 0.64 & (0.31-0.89) \\ \text { MIGLIORI [8] } & 0.75 & (0.19-0.99) \\ \text { PARK [45] } & 0.71 & (0.29-0.96) \\ \text { SCHECTER [30] } & 0.96 & (0.78-1.00) \\ \text { SINGLA [31] } & 0.64 & (0.35-0.87) \\ \text { UdWADIA [32] } & 0.92 & (0.64-1.00) \\ \text { VILLAR [33] } & 0.89 & (0.52-1.00) \\ \text { VON DER LIPPE [44] } & 0.90 & (0.55-1.00)\end{array}$

Pooled proportion $=0.82(0.74-0.88)$

Chi-squared $=19.92 ; \mathrm{df}=11 \quad(\mathrm{p}=0.0464)$

$\left.\right|^{2}=44.8 \%$

FIGURE 4. Forest plot showing the proportion of patients who were successfully treated in the enrolled studies. Data are presented as $n(95 \% \mathrm{Cl}) ; l^{2}$ : inconsistency statistics; df: degrees of freedom.

concentration-time curve over $24 \mathrm{~h} / \mathrm{MIC}$ ratios were sufficiently high $(>100)$ to predict efficacy in seven out of the eight patients studied. This study provides evidence that a $300 \mathrm{mg}$ b.i.d. dosage may be used to prolong treatment with linezolid, with sustained efficacy and limitation of adverse events.

While properly designed randomised pharmacokinetic studies on larger samples (including comparison of outcomes) will give a final answer on the ideal dose of linezolid, it seems rational to perform kinetics on all cases exposed to the drug [35].
Although very expensive, linezolid is used off-label, with extremely prolonged duration of exposure, beyond its licensed prescription length of 28 days [47]. In this international cohort the median duration of linezolid treatment was 300 days (589.5 days versus 252 days in the group treated with linezolid $\leqslant 600 \mathrm{mg}$ q.d. and $>600 \mathrm{mg}$ b.i.d., respectively). In two studies linezolid was prescribed for the entire treatment duration, e.g. from 18.6 months to 20.6 months [30,32]. The optimum duration of linezolid use is still unknown. Administration of linezolid for a shorter duration of time is likely to reduce the occurrence of

TABLE 6 Retrospective evaluation of the safety and tolerability of linezolid in 121 multidrug-resistant tuberculosis cases

\begin{tabular}{|c|c|c|c|c|}
\hline & Total & LNZ daily dose $\leqslant 600 \mathrm{mg}$ & LNZ daily dose $>600 \mathrm{mg}$ & $p$-value \\
\hline Patients exposed to LNZ & & $72(59.5)$ & 49 (40.5) & \\
\hline Major adverse events & $54 / 79(68.4)$ & $27 / 44(61.4)$ & $27 / 35(77.1)$ & 0.14 \\
\hline Anaemia & 32/84 (38.1) & 11/49 (22.5) & $21 / 35(60.0)$ & 0.0005 \\
\hline Leukopoenia & 7/85 (8.2) & $1 / 50(2.0)$ & $6 / 35(17.1)$ & 0.012 \\
\hline Optic neuritis & 10/76 (13.2) & $4 / 41(9.8)$ & 6/35 (17.1) & 0.35 \\
\hline Gastro-intestinal disorders & $14 / 84(16.7)$ & $4 / 50(8.0)$ & 10/34 (29.4) & 0.01 \\
\hline Exposure to LNZ days & $300(140-690)$ & $589.5(154.5-750)$ & $252(120-540)$ & 0.031 \\
\hline
\end{tabular}

Data are presented as $\mathrm{n} / \mathrm{N}(\%)$ or median (interquartile range), unless otherwise stated. LNZ: linezolid. 
a)

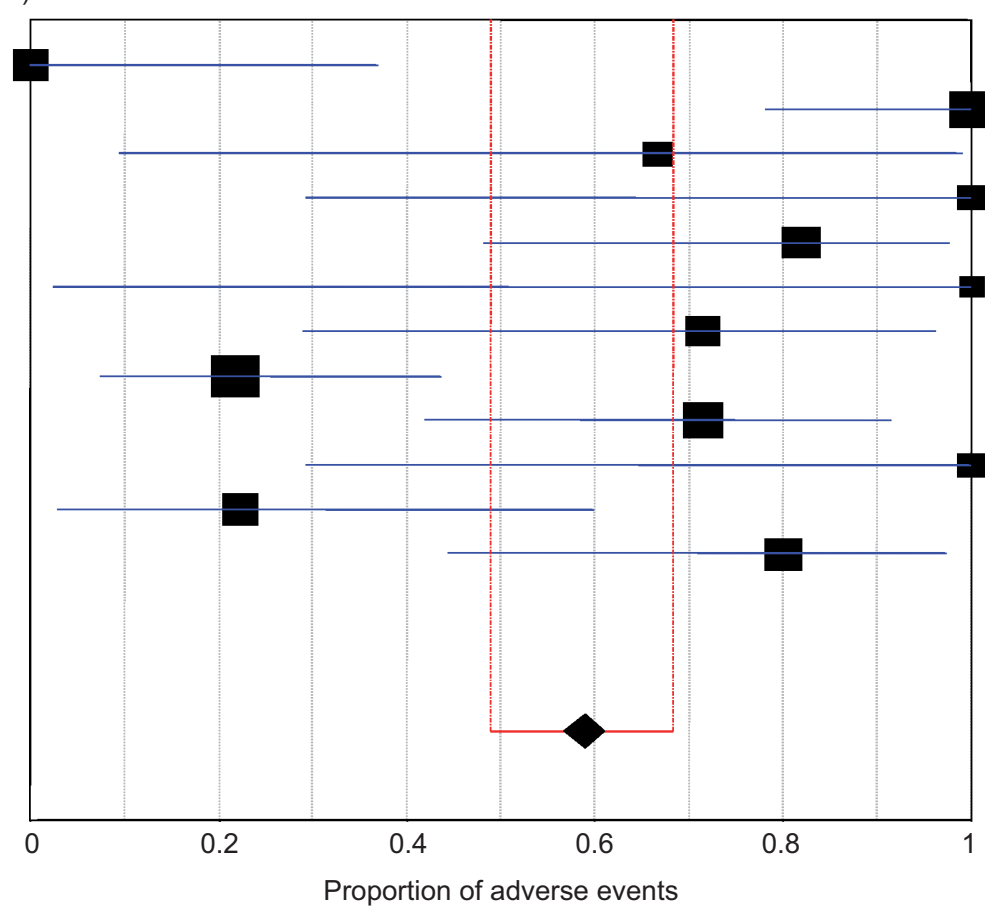

b)

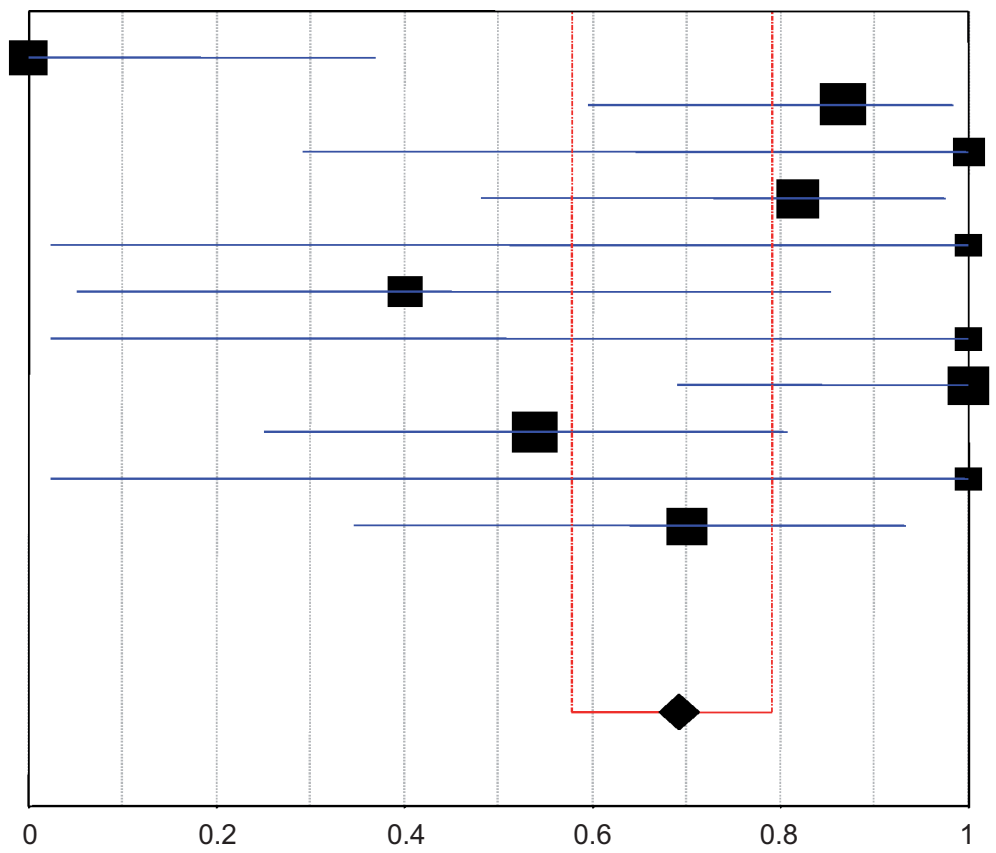

Proportion of linezolid interruption due to adverse events

First author [ref.] Proportion of adverse events

$\begin{array}{lll}\text { ALFFENAAR [47] } & 0.00 & (0.00-1.37) \\ \text { ANGER [34] } & 1.00 & (0.78-1.00) \\ \text { DE LORENZO [35] } & 0.67 & (0.09-0.99) \\ \text { FORTÚN [22] } & 1.00 & (0.29-1.00) \\ \text { NAM [46] } & 0.82 & (0.48-0.98) \\ \text { MIGLIORI [8] } & 1.00 & (0.03-1.00) \\ \text { PARK [45] } & 0.71 & (0.29-0.96) \\ \text { SCHECTER [30] } & 0.22 & (0.07-0.44) \\ \text { SINGLA [31] } & 0.71 & (0.29-1.00) \\ \text { UDWADIA [32] } & 1.00 & (0.35-0.87) \\ \text { VILLAR [33] } & 0.22 & (0.03-0.60) \\ \text { VON DER LIPPE [44] } & 0.80 & (0.44-0.97)\end{array}$

Pooled proportion $=0.59(0.49-0.68)$

Chi-squared $=61.94 ; \mathrm{df}=11 \quad(\mathrm{p}=0.0000)$

$\mathrm{I}^{2}=82.2 \%$

First author

[ref.]

AlfFEnAAR [47]

ANGER [34]

FORTÚN [22]

NAM [46]

MIGLIORI [8]

PARK [45]

SCHECTER [30]

SINGLA [31]

UDWADIA [32]

VILLAR [33]

VON DER LIPPE [44]
Proportion of linezolid interruption due to averse events

$\begin{array}{ll}0.00 & (0.00-0.37) \\ 0.87 & (0.60-0.98) \\ 1.00 & (0.29-1.00) \\ 0.82 & (0.48-0.98) \\ 1.00 & (0.03-1.00) \\ 0.40 & (0.05-0.85) \\ 1.00 & (0.03-1.00) \\ 1.00 & (0.69-1.00) \\ 0.54 & (0.25-0.81) \\ 1.00 & (0.03-1.00) \\ 0.70 & (0.35-0.93)\end{array}$

Pooled proportion $=0.69(0.58-0.79)$

Chi-squared=37.19; $d f=10 \quad(p=0.0001)$

$\mathrm{I}^{2}=73.1 \%$

FIGURE 5. Forest plots showing a) the proportion of patients affected by adverse events and b) the proportion of patients who interrupted their treatment owing to adverse events in the enrolled studies, respectively. Data are presented as $n(95 \% \mathrm{Cl})$; I $^{2}$ : inconsistency statistics; df: degrees of freedom.

adverse events, but may compromise efficacy and/or increase likelihood of acquired resistance. More information on this topic is needed and cannot be drawn from the observational studies carried out to date.

\section{Efficacy, safety and tolerability}

Linezolid proved to be successful when added to a DSTtailored, individualised treatment regimen composed of several drugs. The pooled estimates of anti-TB treatment success and 
a)

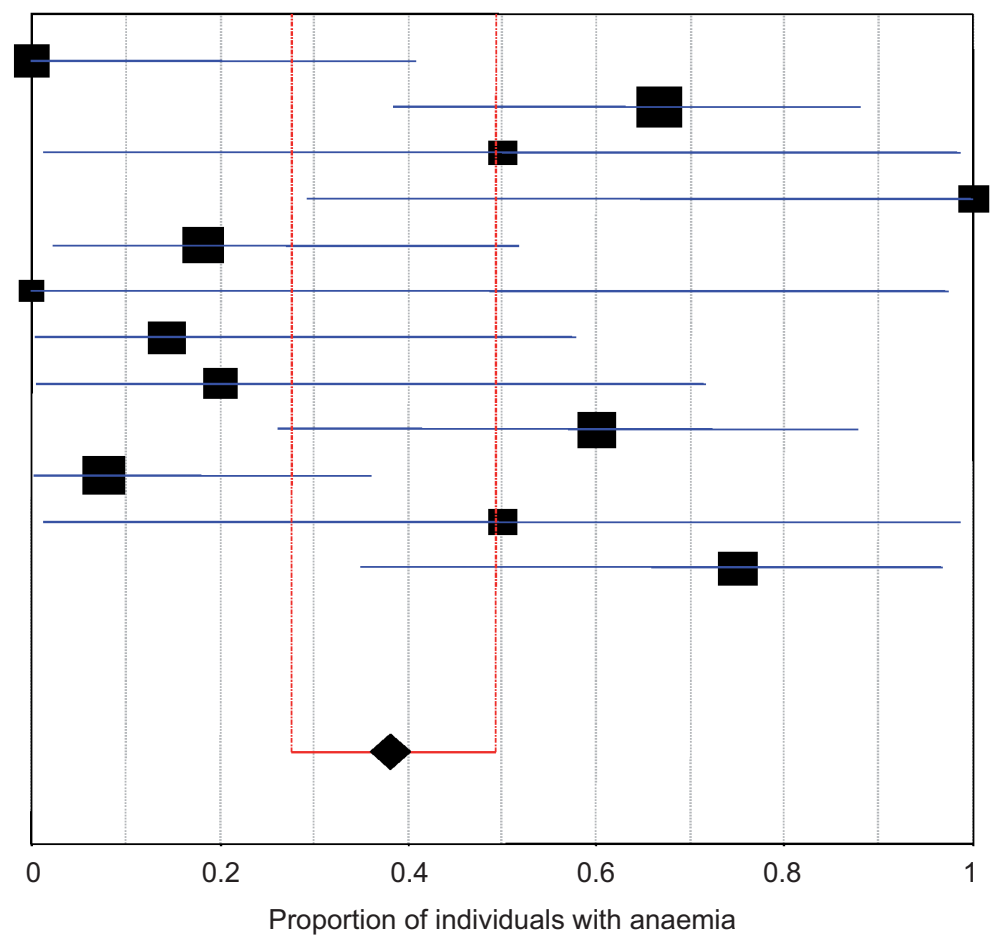

b)

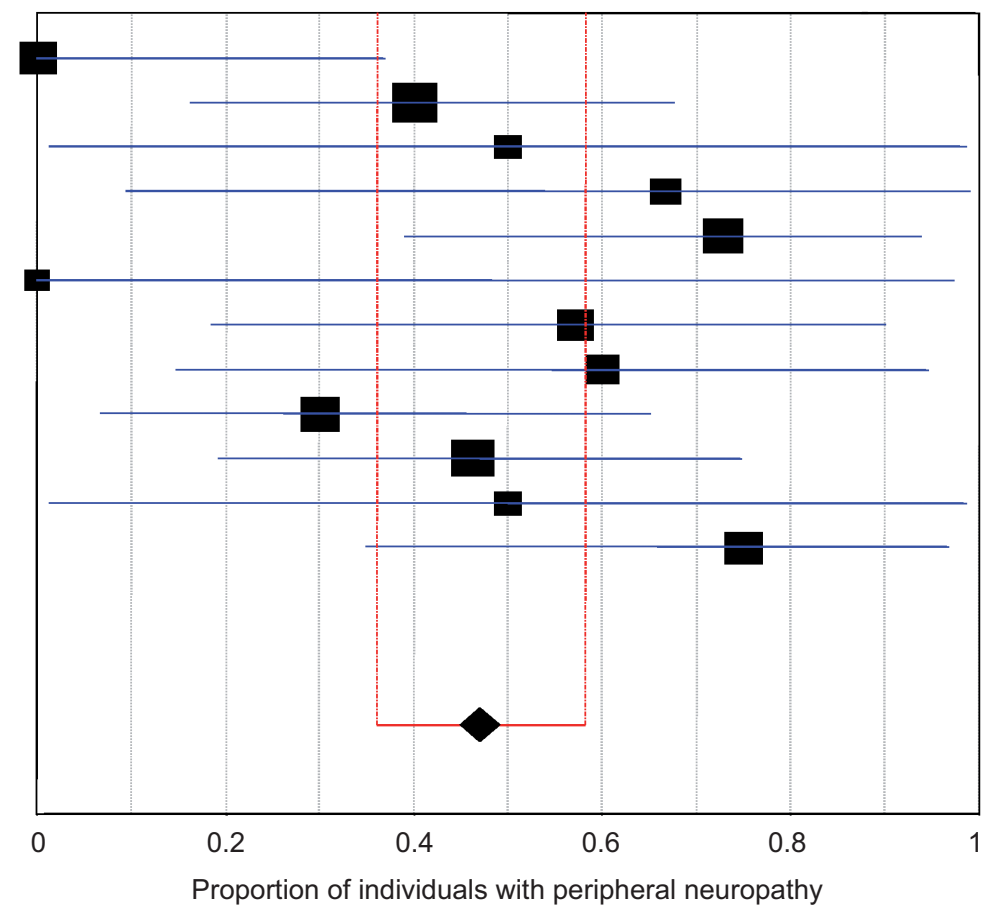

First author [ref.] Proportion of individuals with anaemia

AlffenaAr [47]

$0.00 \quad(0.00-0.41)$

ANGER [34]

$0.67 \quad(0.38-0.88)$

DE LoREnZo [35]

$0.50 \quad(0.01-0.99)$

FORTÚN [22]

$1.00 \quad(0.29-1.00)$

NAM [46]

$0.18 \quad(0.02-0.52)$

MIGLIORI [8]

$0.00 \quad(0.00-0.98)$

PARK [45]

$0.14 \quad(0.00-0.58)$

SCHECTER [30]

$0.20 \quad(0.01-0.72)$

SINGLA [31]

$0.60 \quad(0.26-0.88)$

UDWADIA [32]

$0.08 \quad(0.00-0.36)$

VILLAR [33]

$0.50 \quad(0.01-0.99)$

VON DER LIPPE [44]

$0.75 \quad(0.35-0.97)$

Pooled proportion $=0.38(0.28-0.49)$

Chi-squared $=36.31 ; d f=11 \quad(p=0.0001)$

$\mathrm{I}^{2}=69.7 \%$

First author [ref.] Proportion of individuals with peripheral neuropathy

AlfFenAar [47]

$\begin{array}{ll}0.00 & (0.00-0.37) \\ 0.40 & (0.16-0.68) \\ 0.50 & (0.01-0.99) \\ 0.67 & (0.09-0.99) \\ 0.73 & (0.39-0.94) \\ 0.00 & (0.00-0.98) \\ 0.57 & (0.18-0.90) \\ 0.60 & (0.15-0.95) \\ 0.30 & (0.07-0.65) \\ 0.46 & (0.19-0.75) \\ 0.50 & (0.01-0.99) \\ 0.75 & (0.35-0.97)\end{array}$

Pooled proportion $=0.47(0.36-0.58)$

Chi-squared $=19.64 ; d f=11 \quad(p=0.0505)$

$\mathrm{I}^{2}=44.0 \%$
DE LORENZO [35]

FORTÚN [22]

NAM [46]

MIGLIORI [8]

PARK [45]

SCHECTER [30]

SINGLA [31]

UDWADIA [32]

VILLAR [33]

VOH DER LIPPE [44]
$(0.35-0.97)$

FIGURE 6. Forest plots showing a) the proportion of individuals affected by anaemia and b) the proportion of individuals affected by peripheral neuropathy in the enrolled studies. Data are presented as $\mathrm{n}(95 \% \mathrm{Cl}) ; \mathrm{I}^{2}$ : inconsistency statistics; df: degrees of freedom. 
culture conversion were $82 \%$ and $93 \%$, respectively. Median time to sputum smear and culture conversion were 43.5 days and 61 days, respectively.

In spite of some variability, all studies included high percentages of severe MDR-TB cases and XDR-TB patients; the pooled proportion of XDR-TB cases was $32.5 \%$ with an inconsistency of $67.0 \%$, reflecting the different prescription habits of the settings where the studies were performed. Success was comparable between patients receiving a daily linezolid dose $\leqslant 600 \mathrm{mg}$ and those having a higher dose, notwithstanding the finding that patients with definitional XDR-TB, and who would be expected to have a lower likelihood of success than other MDR-TB patients, were similarly distributed between the two treatment groups.

On the other side, the study results confirm that administration of linezolid is hampered by several toxic effects, although a large variation in major adverse events has been observed. As discussed previously, toxicity was dose-dependent, being lower when a dose $\leqslant 600 \mathrm{mg}$ q.d. was used [47]. In eight out of the 12 studies analysed $\geqslant 25 \%$ of the cases reported major adverse events, making interruption of the drug (or re-adjustment of its dosage) necessary. The meta-analysis showed that the pooled proportion of any adverse event was 59\%, of which $69 \%$ were major adverse events.

\section{Strengths and weaknesses}

The systematic review was based on a sample size of 207 cases taken from three continents and 11 countries (Belarus, Germany, India, Italy, South Korea, the Netherlands, Norway, Portugal, Spain Switzerland and USA).

The meta-analysis on individual data included a large sample size $(n=121$ cases), representing all the cases having a definite outcome (with the single exception of the Germany cases, which belonged to the largest data-set [8]). Although no specific cohort from Africa and Latin America is available, a proportion of cases born in these continents were included in our study $(8 \%$ and $6.7 \%$, respectively).

The individual data-set allowed the analysis of all the variables planned, so that the final conclusions were sufficiently robust and, although not necessarily representative, they could be cautiously generalised. Furthermore, subgroup analyses were performed in two comparable cohorts, apart from a few statistically significant differences of some demographic, epidemiological and clinical variables. The meta-analysis is based non-controlled, nonrandomised, unblinded observational data; consequently, a selection bias cannot be excluded in the original studies, as well as publication bias.

Furthermore, owing to the retrospective nature of the majority of the enrolled studies, the efficacy of linezolid was not weighted for the anti-TB drug-combinations and for other clinical and epidemiological confounding variables. The proportion of favourable outcomes is likely to be under-represented if linezolid has been used as a salvage drug, than if it has been prescribed in less compromised patients who could better tolerate adverse events.

In addition the wide time span in which the reviewed studies occurred is unlikely to have biased the results. Consequently this global study adds new information, which was not available in either the largest single study to date [8] or in the other selected smaller studies [30-35, 44-47].

\section{Conclusions}

The results of our study suggest an excellent efficacy but also the necessity of caution in the prescription of linezolid for treatment of MDR-TB. Although effective in treating MDR-TB and XDR-TB cases, its administration should be limited to severe cases when an additional active anti-TB drug is needed. Its role in the future generation of shorter regimens needs to be further assessed, although the drug characteristics do not support an easy outpatient-based use in combination with the new drugs, which are expected to be launched onto the market in the near future. A dosage of $\leqslant 600 \mathrm{mg}$ per day (either as a single dose or divided into two doses) seems the best recommendation, as it minimises the occurrence of adverse events while not compromising efficacy. The high proportion of cases experiencing adverse events and requiring drug interruption or dosage reduction suggests that the use of linezolid should be limited to specialised MDR-TB reference centres, where both inpatients and outpatients can be carefully monitored for any occurrence of serious adverse events and where facilities are well equipped to manage any serious problem (including the possible need for blood transfusion).

\section{SUPPORT STATEMENT}

Current Research Funds from participating institutions and European Community's Seventh Framework Programme (FP7/2007-2013) under Grant Agreement FP7-223681.

\section{STATEMENT OF INTEREST}

None declared.

\section{ACKNOWLEDGEMENTS}

The affiliation details for the authors are as follows: G. Sotgiu and P. Castiglia: Epidemiology and Medical Statistics Unit, Dept of Biomedical Sciences, University of Sassari, Sassari, Italy; R. Centis, L. D'Ambrosio, E. Zampogna and G.B. Migliori: World Health Organization Collaborating Centre for Tuberculosis and Lung Diseases, Fondazione S. Maugeri, Care and Research Institute, Tradate, Italy; J-W.C. Alffenaar: University of Groningen, University Medical Center Groningen, Dept of Hospital and Clinical Pharmacy, Groningen, the Netherlands; H.A. Anger: New York City Dept of Health and Mental Hygiene, Bureau of Tuberculosis Control, New York, NY, USA; J.A. Caminero: MDR-TB Unit, Dept of Pneumology, University General Hospital of Gran Canaria "Dr. Negrin", Las Palmas de Gran Canaria, Spain and International Union against Tuberculosis and Lung Disease (The Union), Paris, France; S. De Lorenzo: AOVV E. Morelli Hospital, Reference Hospital for MDR and HIV-TB, Sondalo, Italy; G. Ferrara: Lung Allergi Kliniken, Karolinska University Hospital, Stockholm, Sweden, and Section of Respiratory Diseases, Dept of Internal Medicine, University of Perugia, Terni, Italy; W-J. Koh: Division of Pulmonary and Critical Care Medicine, Dept of Medicine, Samsung Medical Center, Sungkyunkwan University School of Medicine, Seoul, Republic of Korea; G.F. Schecter: Tuberculosis Control Branch, Division of Communicable Disease Control, Center for Infectious Disease, California Dept of Public Health, Richmond, CA, USA; T.S. Shim: Division of Pulmonary and Critical Care Medicine, University of Ulsan College of Medicine, Asan Medical Center, Seoul, Republic of Korea; R. Singla: Dept of Tuberculosis and Chest Diseases, Lala Ram Sarup Institute of Tuberculosis and Respiratory Diseases, New Delhi, India; A. Skrahina: Clinical Dept, National Research and Practical Centre for Pulmonology and Tuberculosis, Minsk, Belarus: A. Spanevello: Università degli Studi dell'Insubria, Varese, and Fondazione S. Maugeri, Care and Research Institute, Tradate, Italy; Z.F. 
Udwadia: Dept of Pulmonary medicine, P.D. Hinduja National Hospital and Medical Research Centre, Veer Savarkar Marg, Mahim, Mumbai, India; M. Villar: Lung Diseases Centre of Venda Nova, Amadora, Portugal; J-P. Zellweger: TB Clinic, Dept of Ambulatory Care and Community Medicine, University of Lausanne, Lausanne, Switzerland; A. Zumla: Dept of Infection, Division of Infection and Immunity, Centre for Clinical Microbiology, University College London, London, UK.

\section{REFERENCES}

1 World Health Organization. Multidrug and Extensively DrugResistant TB (M/XDR-TB): 2010 Global Report on Surveillance and Response. Publication No. WHO/HTM/TB/2010.3. Geneva, World Health Organization, 2010. Available from: http://whqlibdoc. who.int/publications/2010/9789241599191_eng.pdf

2 World Health Organization. Global Tuberculosis Control 2011: WHO Report 207. Publication No. WHO/HTM/TB/2011.16. Geneva, World Health Organization, 2011. Available from: http:// whqlibdoc.who.int/publications/2011/9789241564380_eng.pdf

3 Extensively drug-resistant tuberculosis (XDR-TB): recommendations for prevention and control. Wkly Epidemiol Rec 2006; 81: 430-432.

4 Centers for Disease Control and Prevention. Emergence of Mycobacterium tuberculosis with extensive resistance to second-line drugs - worldwide, 2000-2004. MMWR Morb Mortal Wkly Rep 2006; 55: 301-305.

5 Migliori GB, Lange C, Girardi E, et al. Fluoroquinolones: are they essential to treat multidrug-resistant tuberculosis? Eur Respir J 2008; 31: 904-905.

6 Migliori GB, Lange C, Centis R, et al. Resistance to second-line injectables and treatment outcomes in multidrug-resistant and extensively drug-resistant tuberculosis cases. Eur Respir J 2008; 31: $1155-1159$.

7 Sotgiu G, Ferrara G, Matteelli A, et al. Epidemiology and clinical management of XDR-TB: a systematic review by TBNET. Eur Respir J 2009; 33: 871-881.

8 Migliori GB, Eker B, Richardson MD, et al. A retrospective TBNET assessment of linezolid safety, tolerability and efficacy in multidrug-resistant tuberculosis. Eur Respir J 2009; 34: 387-393.

9 Migliori GB, Besozzi G, Girardi E, et al. Clinical and operational value of the extensively drug-resistant tuberculosis definition. Eur Respir J 2007; 30: 623-626.

10 Mitnick CD, Shin SS, Seung KJ, et al. Comprehensive treatment of extensively drug-resistant tuberculosis. N Engl J Med 2008; 359: 563-574.

11 Keshavjee S, Gelmanova IY, Farmer PE, et al. Treatment of extensively drug-resistant tuberculosis in Tomsk, Russia: a retrospective cohort study. Lancet 2008; 372: 1403-1409.

12 Kim DH, Kim HJ, Park SK, et al. Treatment outcomes and longterm survival in patients with extensively drug resistant tuberculosis. Am J Respir Crit Care Med 2008; 178: 1075-1082.

13 Caminero JA, Sotgiu G, Zumla A, et al. Best drug treatment for multidrug-resistant and extensively drug-resistant tuberculosis. Lancet Infect Dis 2010; 10: 621-629.

14 Falzon D, Jaramillo E, Schünemann HJ, et al. WHO guidelines for the programmatic management of drug-resistant tuberculosis: 2011 update. Eur Respir J 2011; 38: 516-528.

15 Yew WW, Lange C, Leung CC. Treatment of tuberculosis: update 2010. Eur Respir J 2011; 37: 441-462.

16 Williams KN, Stover CK, Zhu T, et al. Promising antituberculosis activity of the oxazolidinone PNU-100480 relative to that of linezolid in a murine model. Antimicrob Agents Chemother 2009; 53: 1314-1319.

17 Tato M, de la Pedrosa EG, Cantón R, et al. In vitro activity of linezolid against Mycobacterium tuberculosis complex, including multidrug-resistant Mycobacterium bovis isolates. Int J Antimicrob Agents 2006; 28: 75-78
18 Erturan Z, Uzun M. In vitro activity of linezolid against multidrugresistant Mycobacterium tuberculosis isolates. Int J Antimicrob Agents 2005; 26: 78-80.

19 Alcalá L, Ruiz-Serrano MJ, Pérez-Fernández Turégano C, et al. In vitro activities of linezolid against clinical isolates of Mycobacterium tuberculosis that are susceptible or resistant to first-line antituberculous drugs. Antimicrob Agents Chemother 2003; 47: 416-417.

20 Rodríguez JC, Ruiz M, López M, et al. In vitro activity of moxifloxacin, levofloxacin, gatifloxacin and linezolid against Mycobacterium tuberculosis. Int J Antimicrob Agents 2002; 20: 464-467.

21 Diekema DJ, Jones RN. Oxazolidinone antibiotics. Lancet 2001; 358 : 1975-1982.

22 Fortún J, Martín-Dávila P, Navas E, et al. Linezolid for the treatment of multidrug-resistant tuberculosis. J Antimicrob Chemother 2005; 56: 180-185.

23 Dietze R, Hadad DJ, McGee B, et al. Early and extended early bactericidal activity of linezolid in pulmonary tuberculosis. Am J Respir Crit Care Med 2008; 178: 1180-1185.

24 Nannini EC, Keating M, Binstock P, et al. Successful treatment of refractory disseminated Mycobacterium avium complex infection with the addition of linezolid and mefloquine. J Infect 2002; 44: 201-203.

25 Brown-Elliott BA, Wallace RJ Jr, Blinkhorn R, et al. Successful treatment of disseminated Mycobacterium chelonae infection with linezolid. Clin Infect Dis 2001; 33: 1433-1434.

26 Morales P, Ros JA, Blanes M, et al. Successful recovery after disseminated infection due to Mycobacterium abscessus in a lung transplant patient: subcutaneous nodule as first manifestation - a case report. Transplant Proc 2007; 39: 2413-2415.

27 Hoetzenecker W, Ulmer A, Klingel K, et al. Dissemination of a localized cutaneous infection with Mycobacterium chelonae under immunosuppressive treatment. Arch Dermatol 2007; 143: 951-952.

28 Kyle SD, Porter WM. Mycobacterium chelonae infection successfully treated with oral clarithromycin and linezolid. Br J Dermatol 2004; 151: 1101.

29 Ntziora F, Falagas ME. Linezolid for the treatment of patients with atypical mycobacterial infection: a systematic review. Int J Tuberc Lung Dis 2007; 11: 606-611.

30 Schecter GF, Scott C, True L, et al. Linezolid in the treatment of multidrug-resistant tuberculosis. Clin Infect Dis 2010; 50: 49-55.

31 Singla R, Caminero JA, Jaiswal A, et al. Linezolid, an effective, safe and cheap drug for patients failing multidrug-resistant tuberculosis treatment in India. Eur Respir J 2012; 39: 956-962.

32 Udwadia ZF, Sen T, Moharil G. Assessment of linezolid efficacy and safety in MDR- and XDR-TB: an Indian perspective. Eur Respir J 2010; 35: 936-938.

33 Villar M, Sotgiu G, D'Ambrosio L, et al. Linezolid safety, tolerability and efficacy to treat multidrug- and extensively drug-resistant tuberculosis. Eur Respir J 2011; 38: 730-733.

34 Anger HA, Dworkin F, Sharma S, et al. Linezolid use for treatment of multidrug-resistant and extensively drug-resistant tuberculosis, New York City, 2000-06. J Antimicrob Chemother 2010; 65: 775-783.

35 De Lorenzo S, Centis R, D'Ambrosio L, et al. On linezolid efficacy and tolerability. Eur Respir J 2012; 39: 770-772.

36 Lönnroth K, Castro KG, Chakaya JM, et al. Tuberculosis control and elimination 2010-50: cure, care, and social development. Lancet 2010; 375: 1814-1829.

37 Gandhi NR, Nunn P, Dheda K, et al. Multidrug- resistant and extensively drug resistant tuberculosis: a threat to global control of tuberculosis. Lancet 2010; 375: 1830-1843.

38 Yew WW, Chau $\mathrm{CH}$, Wen KH. Linezolid in the treatment of "difficult" multidrug-resistant tuberculosis. Int J Tuberc Lung Dis 2008; 12: 345-346.

39 Yew WW, Chang KC, Chau CH. What is the optimal dosage of linezolid in treatment of complicated multidrug-resistant tuberculosis? Eur Respir J 2009; 34: 1492-1494. 
40 Sotgiu G, Lange C, Richardson MD, et al. Comment on: Daily $300 \mathrm{mg}$ dose of linezolid for the treatment of intractable multidrug-resistant and extensively drug-resistant tuberculosis. J Antimicrob Chemother 2009; 64: 879-883.

41 Laserson KF, Thorpe LE, Leimane V, et al. Speaking the same language: treatment outcome definitions for multidrug-resistant tuberculosis. Int J Tuberc Lung Dis 2005; 9: 640-645.

42 Moher D, Liberati A, Tetzlaff J, et al. Preferred reporting items for systematic reviews and meta-analyses: the PRISMA statement. PLoS Med 2009; 6: e1000097.

43 Zamora J, Abraira V, Muriel A, et al. Meta-DiSc: a software for meta-analysis of test accuracy data. BMC Med Res Methodol 2006; 6: 31 .
44 von der Lippe B, Sandven P, Brubakk O. Efficacy and safety of linezolid in multidrug resistant tuberculosis (MDR-TB)-a report of ten cases. J Infect 2006; 52: 92-96.

45 Park IN, Hong SB, Oh YM, et al. Efficacy and tolerability of dailyhalf dose linezolid in patients with intractable multidrug-resistant tuberculosis. J Antimicrob Chemother 2006; 58: 701-704.

46 Nam HS, Koh WJ, Kwon OJ, et al. Daily half-dose linezolid for the treatment of intractable multidrug-resistant tuberculosis. Int $J$ Antimicrob Agents 2009; 33: 92-93.

47 Alffenaar JW, van Altena R, Harmelink IM, et al. Comparison of the pharmacokinetics of two dosage regimens of linezolid in multidrug-resistant and extensively drug-resistant tuberculosis patients. Clin Pharmacokinet 2010; 49: 559-565. 